\title{
THE LASTING EFFECTS OF ADAPTIVE PLASTICITY: PREDATOR-INDUCED TADPOLES BECOME LONG-LEGGED FROGS
}

\author{
Rick A. RELYEA ${ }^{1}$ \\ Department of Biology, University of Michigan, Ann Arbor, Michigan 48109 USA
}

\begin{abstract}
Changes in environmental conditions often alter the traits of individuals; however, we have a poor understanding of how changes in phenotypically plastic traits early in development may affect traits later in life. Such effects are of particular interest in organisms with complex life cycles in which early and late life stages can have drastically different morphologies and occupy different habitats. In this study, I examined how differences in the mass, morphology, and larval period of wood frog tadpoles (Rana sylvatica) subsequently affected the mass and morphology of metamorphic frogs. I found three major patterns: (1) larval mass and larval period were positively related to metamorphic mass; (2) larval period was positively related to metamorph hindlimb and forelimb length and negatively related to metamorph body width; and (3) larval body length was positively related to metamorph forelimb size. I then used these correlations to interpret the connection between the traits of predator-induced tadpoles and the subsequent traits of metamorphic frogs. Tadpoles reared with caged predators (aeshnid dragonflies) developed relatively deeper tail fins and had shorter bodies, lower mass, and longer developmental times than tadpoles reared without predators. Metamorphs emerging from larval predator environments exhibited no differences in mass but developed relatively large hindlimbs and forelimbs and narrower bodies than metamorphs emerging from predator-free larval environments. These differences arose primarily due to predator-induced changes in larval development time and not due to the predator-induced changes in larval morphology. By focusing on a large number of traits and a wide range of trait values, one can readily generate predictions about how a variety of environments, which alter traits early in development, can subsequently alter traits later in development.
\end{abstract}

Key words: anura; development; heterochrony; metamorph; morphology; ontogeny; phenotypic plasticity; predator; Rana sylvatica; tadpole; wood frog.

\section{INTRODUCTION}

When an organism with phenotypic plasticity expresses alternative phenotypes in different environments, the plastic response typically alters the organism's fitness (Roff 1992, Stearns 1992, Schlichting and Pigliucci 1998, Tollrian and Harvell 1999). There has been a growing interest in the effects of alternative environments on the traits (e.g., behavior, morphology, or physiology) and performance (e.g., growth, development, or survivorship) of phenotypically plastic individuals, because these effects allow us to address whether phenotypic responses are adaptive (that is, whether they are maintained by natural selection; Dudley and Schmitt 1996). However, environments that affect traits and performance early in development also may affect traits and performance later in development.

There have been a number of investigations examining the impact of early environments on late-stage traits and performance. For example, larval temperature and photoperiod affect the propensity for diapause

Manuscript received 3 January 2000; revised 25 May 2000; accepted 19 June 2000; final version received 11 August 2000.

${ }^{1}$ Present address: Department of Biological Sciences, University of Pittsburgh, Pittsburgh, Pennsylvania 15260 USA. E-mail: relyea+@ pitt.edu and changes in adult morphology in many arthropods (Taylor 1986, Crill et al. 1996, de Moed et al. 1997), resource levels play a major role in the production of winged offspring and dispersal in some insects (Richards and Waloff 1954, Harrison 1980, Roff 1986, Denno and Roderick 1992), and predator cues present during egg development in Daphnia cause defensive spine formation later in development (Spitze 1992, Tollrian 1995). In each of these cases, the late-stage response to an early environment is thought to be adaptive; the organisms enjoy fitness benefits because the early environmental conditions are predictive of future environmental conditions. However, for many organisms, larval environments may not be predictive of adult environmental conditions. For example, many amphibians and insects spend their larval stage in an aquatic environment and their adult stage in a terrestrial environment; in this case, the larval environment likely predicts little about the adult environment for most abiotic and biotic factors. However, larval environments might still affect adult traits and performance simply because larval environments alter larval traits and because larval traits are developmentally tied to adult traits. In this case, the effect on adult fitness could be positive, negative, or neutral.

To understand how this latter scenario could manifest 
itself, we must develop an understanding of how larval environments affect larval traits and how larval traits are developmentally tied to adult traits. With these two pieces of information, we can then predict how any change in the larval environment will indirectly alter the traits of adults. Thus, it provides us with mechanistic hypotheses for the developmental pathways that connect larval and adult traits. Moreover, if we correctly identify the pathways, then we can predict how a variety of different larval environments should affect adult traits.

To document the relationship between larval and adult traits, one needs to begin with a wide range of early morphological trait values that can be correlated against the subsequent late morphological trait states. One approach to generating a wide range of phenotypes is to take advantage of both genetic and environmentally induced variation in phenotypes (Roff 1998, Schlichting and Pigliucci 1998, Tollrian and Harvell 1999). Significant correlations between early and late traits can then be used to suggest mechanistic pathways that connect these two life stages.

Larval anurans represent an excellent model system to investigate this question because environmentally induced tadpole morphology is well investigated (Smith and Van Buskirk 1995, Van Buskirk et al. 1997, Van Buskirk and Relyea 1998, Relyea 2000, Relyea and Werner 2000, Relyea 2001a, b), and larvae can be reared through metamorphosis to determine how changes in tadpole morphology translate into changes in metamorph morphology. However, we know little about how changes in larval environments might affect metamorph morphology (Emerson 1986, Blouin and Loeb 1991). Further, because amphibians also possess a great deal of genetic variation (Berven 1982a, $b$, Travis et al. 1987, Semlitsch et al. 1990, Bernardo 1994, Maurer and Sih 1996, Relyea 2002), we can use them to generate a wide range of tadpole phenotypes and determine the relationship between tadpole morphology and metamorph morphology. In this study, I used wood frogs (Rana sylvatica) to examine potential developmental pathways between larval traits (mass, morphology, and developmental rate) and metamorph traits (mass and morphology). I then used these relationships to understand how predators, which alter larval traits, indirectly affect the traits of the metamorphs.

\section{Methods}

Wood frogs were collected on 17-19 April 1996 as eggs from eight different ponds (three masses per pond) on or near the Edwin S. George Reserve in southeast Michigan, USA as part of a larger experiment in which I examined population differences in predator-induced larval traits (Relyea 1998). Four of the populations were from closed-canopy ponds (ponds in which trees shaded the majority of the pond; Southwest Woods Pond, Dreadful Hollow, West Woods Big Pond, and Silver Lake Three Pond), and four of the populations were collected from open-canopy ponds (Cattail Marsh, Buffer Zone Marsh, Gravel Pit Pond, and Pearl Two Pond). These two pond types differ in many biotic and abiotic factors, and, thus, I balanced the design to incorporate both pond types. Each egg mass was hatched separately in pools containing aged well water. Once hatched, 220 hatchlings were randomly sampled from each of the 24 egg masses to be used in the experiment (mean hatchling size per egg mass ranged from 15 to $25 \mathrm{mg}$ ). An additional sample of 20 tadpoles from each egg mass was set aside to determine mortality due to handling; survivorship after $24 \mathrm{~h}$ was $100 \%$.

Tadpoles were reared in pond mesocosms representing predator and predator-free ponds. The mesocosms, set up on 26 April 1996, were 1000-L cattlewatering tanks containing $300 \mathrm{~g}$ of leaves (primarily Quercus spp.), $25 \mathrm{~g}$ of rabbit chow (to serve as an initial nutrient source), and an inoculation of periphyton, phytoplankton, and zooplankton from a nearby pond. Each tank was equipped with four predator cages constructed of $10 \times 10 \mathrm{~cm}$ plastic drain pipe covered on each end with $1 \times 2 \mathrm{~mm}$ fiberglass screening. A small piece of polystyrene was added to each cage to make it float. Each tank was assigned an egg mass and predator treatment in a completely randomized design for a total of 48 tanks (24 egg masses crossed with two predator treatments). On 6 May 1996, the 220 hatchlings from each egg mass were split into one group of 110 (42 hatchlings $/ \mathrm{m}^{2}$ ) reared in a predator tank and one group of 110 reared in a no-predator tank. This density represents a moderate density of wood frogs based upon extensive long-term surveys in southeast Michigan that have documented natural densities of wood frogs from 4 to 253 tadpoles $/ \mathrm{m}^{2}$ (E. E. Werner, R. A. Relyea, D. K. Skelly, and K. L. Yurewicz, unpublished data).

The predators chosen for this experiment were larval dragonflies (Anax longipes and A. junius) collected from a nearby pond. These predators coexist with wood frogs in many ponds and are voracious predators of tadpoles (Van Buskirk and Relyea 1998). For each tank assigned a predator treatment, the four predator cages each contained a single dragonfly in its penultimate instar. Three times per week, I fed the predators $\sim 300$ mg of wood frog tadpoles. For tanks assigned the nopredator treatment, I lifted the empty cages out of the water to equalize disturbance between the two treatments. I fed the predators until 8 July 1996 (63 d of exposure) at which point most tanks had metamorphosing tadpoles. All tanks were covered with shade cloth material that caused $60 \%$ shade and prevented insects and other amphibians from colonizing.

During the wood frog larval stage, three samples were removed to achieve the goals of a larger population experiment (Relyea 1998). Tadpoles were removed after $18 \mathrm{~d}$ (20 tadpoles), $23 \mathrm{~d}$ (40 tadpoles), and $35 \mathrm{~d}$ (20 tadpoles). The last sample represented tadpole morphology just prior to the initiation of metamorphosis (before Gosner stage 42; Gosner 1960). In this last 
sample, tadpoles reared with predators had slower development, lower mass, relatively deeper tails, and relatively longer bodies than tadpoles reared without predators (Relyea 1998). The remaining tadpoles (up to 30) were left in the tanks to metamorphose to meet the objectives of the current study. The first tadpole metamorphosed after $44 \mathrm{~d}$ and the last metamorph appeared after $79 \mathrm{~d}$. Metamorphs were removed at Gosner stages 44-46 (fully developed limbs and a resorbing tail stub) and immediately preserved. The mean time required for all tadpoles to metamorphose from a tank was defined as the mean larval period for that tank.

Morphology was measured by tracing video images of individuals using the BioScan Optimas (Optimas, Bothell, Washington, USA) image analysis program. In Relyea (1998), I describe weighing the tadpoles at 35 $\mathrm{d}$ and measuring several morphological traits: tail depth and length, muscle depth and width, and body depth, length, and width. In the current study, I weighed each metamorph and measured several metamorphic traits from the ventral view: hindlimb length, maximum hindlimb width, upper forelimb length (hereafter termed forelimb length), maximum forelimb width, body length, maximum body width, maximum head width, and mouth width (Fig. 1).

\section{Statistical analysis}

Because the goal of this study was to examine how larval mass, larval period, and relative larval morphology were related to metamorph mass and relative metamorph morphology, I first had to quantify relative morphology. Relative morphology is size independent, and there are a variety of techniques to derive sizeindependent morphology (Bookstein 1989). I derived size-independent morphology by (1) log-transforming the mass and the morphological measurements of all individuals (to improve the linearity of their relationship), (2) conducting a single regression of the logtransformed measurements against log-transformed mass for all individuals, and (3) saving the residuals. I then calculated the mean trait residuals for each experimental unit to serve as the response variables. The same procedure was conducted for both the 35-d larvae and for the metamorphs.

To understand the relationship between larval traits and metamorphic traits, I conducted a multivariate correlation analysis that examined relationships between the nine measured larval traits and the nine measured metamorphic traits. Multivariate test statistics were used to protect against the risk of Type I statistical errors for examining the effect of a larval trait on multiple metamorphic traits. Only when the multivariate tests were significant did I then examine whether any univariate relationships were significant.

Once the relationship between larval and metamorphic traits was established, I examined whether larval predators affected metamorphic traits. To examine the effect of the larval predator environments (and popu-

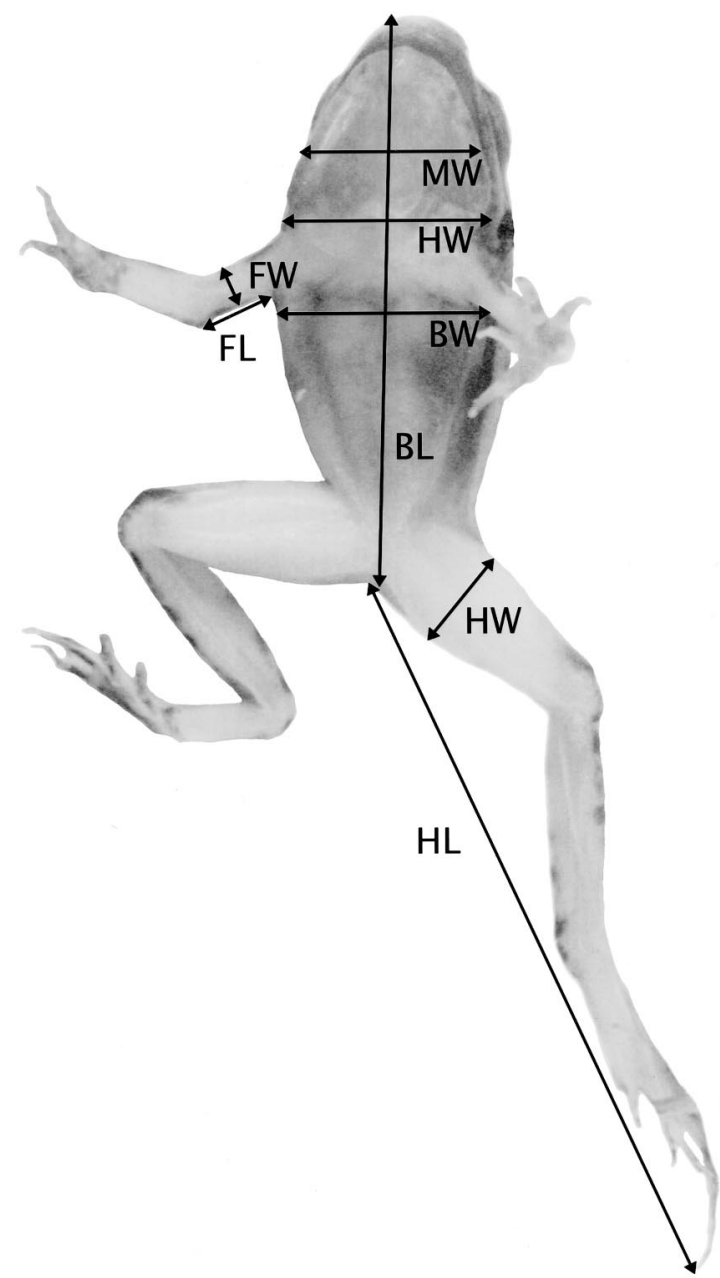

FIG. 1. The morphological dimensions that were measured on wood frog metamorphs reared from eggs collected from eight different ponds on or near the Edwin S. George Reserve in southeast Michigan, USA. HL = hindlimb length (extended straight), HW = hindlimb width, $\mathrm{FL}=$ forelimb length, $\mathrm{FW}=$ forelimb width, $\mathrm{BL}=$ body length, $\mathrm{BW}=$ body width, HW = head width, and MW = mouth width.

lation of origin) on metamorphic traits, I used metamorphic mass and the size-adjusted morphological measurements as response variables in a multivariate analysis of variance (MANOVA; the interaction of population and predator presence was nonsignificant and dropped from the analysis). While this was not an independent test of the predictions based on larval-metamorphic correlations, it allowed me to examine whether predators of larval anurans, which affect larval mass, development, and morphology, also can affect metamorphic traits. Moreover, it allowed me to determine whether the outcome is interpretable from the correlation analysis.

\section{RESULTS}

The correlation analysis, relating larval traits to metamorphic traits, detected significant multivariate ef- 
TABLE 1. Multivariate test statistics from a multiple regression that examined the effect of larval traits (at day 35) on the subsequent metamorphic traits of Rana sylvatica reared from eggs collected from eight different ponds on or near the Edwin S. George Reserve in southeast Michigan, USA.

\begin{tabular}{lccc}
\hline \hline \multicolumn{1}{c}{ Source } & df & Wilks' $F$ & $P$ \\
\hline Larval tail depth & 9,30 & 1.19 & 0.335 \\
Larval tail length & 9,30 & 3.28 & 0.007 \\
Larval muscle depth & 9,30 & 1.28 & 0.288 \\
Larval muscle width & 9,30 & 0.27 & 0.977 \\
Larval body depth & 9,30 & 1.08 & 0.404 \\
Larval body length & 9,30 & 4.15 & 0.001 \\
Larval body width & 9,30 & 1.18 & 0.344 \\
Larval mass & 9,30 & 7.26 & $<0.001$ \\
Larval period & 9,30 & 3.88 & 0.002 \\
\hline
\end{tabular}

Note: The details of the univariate tests for each larval trait are given in the text (see Results).

fects of larval mass, larval period, larval body length, and larval tail length on metamorph morphology (Table 1, Fig. 2). Subsequent univariate tests (Table 2) indicated that larval mass was positively correlated with metamorph mass $(P<0.001)$ but was unrelated to metamorph morphology. Tadpoles with longer larval periods developed into metamorphs with greater mass, relatively longer hindlimbs $(P=0.001)$, longer forelimbs $(P=0.034)$, and narrower bodies $(P=0.030)$. The effect of larval period on hindlimb width was also positive, but the trend was not significant $(P=0.109)$ unless larval period was the only larval trait considered, which increased the power of the test $(P=0.049)$. Tadpoles with longer bodies developed into metamorphs possessing longer $(P=0.003)$ and marginally wider $(P=0.061)$ forelimbs and marginally narrower bodies $(P=0.070)$. Tadpoles with longer tails developed shorter forelimbs $(P=0.003)$ and marginally greater mass $(P=0.066)$ as metamorphs. The remaining five larval traits had no effect on metamorphic traits.

When tadpoles were reared in the presence of predators, metamorphs took an average of $6.2 \mathrm{~d}$ longer to emerge; they possessed relatively longer and wider hindlimbs, longer forelimbs, and a narrower body than metamorphs emerging from predator-free environments. There were no differences in metamorphs mass (Table 3, Fig. 3). In terms of the actual amount of change, hindlimbs were $3.4 \%$ longer (overall mean length = $23.9 \mathrm{~mm}$ ) and $2.7 \%$ wider (overall mean width $=5.5$ $\mathrm{mm}$ ), forelimbs were $2.9 \%$ longer (overall mean length $=2.8 \mathrm{~mm}$ ), and bodies were $3.0 \%$ narrower (overall mean width $=5.5 \mathrm{~mm}$ ). The remaining morphological measurements were not significantly altered by the predator's presence $(P>0.05)$. Metamorphs from different populations differed in relative hindlimb length, hindlimb width, body length, body width, and mouth width.

\section{Discussion}

The results of this study provide insight into how traits expressed early in development can affect traits

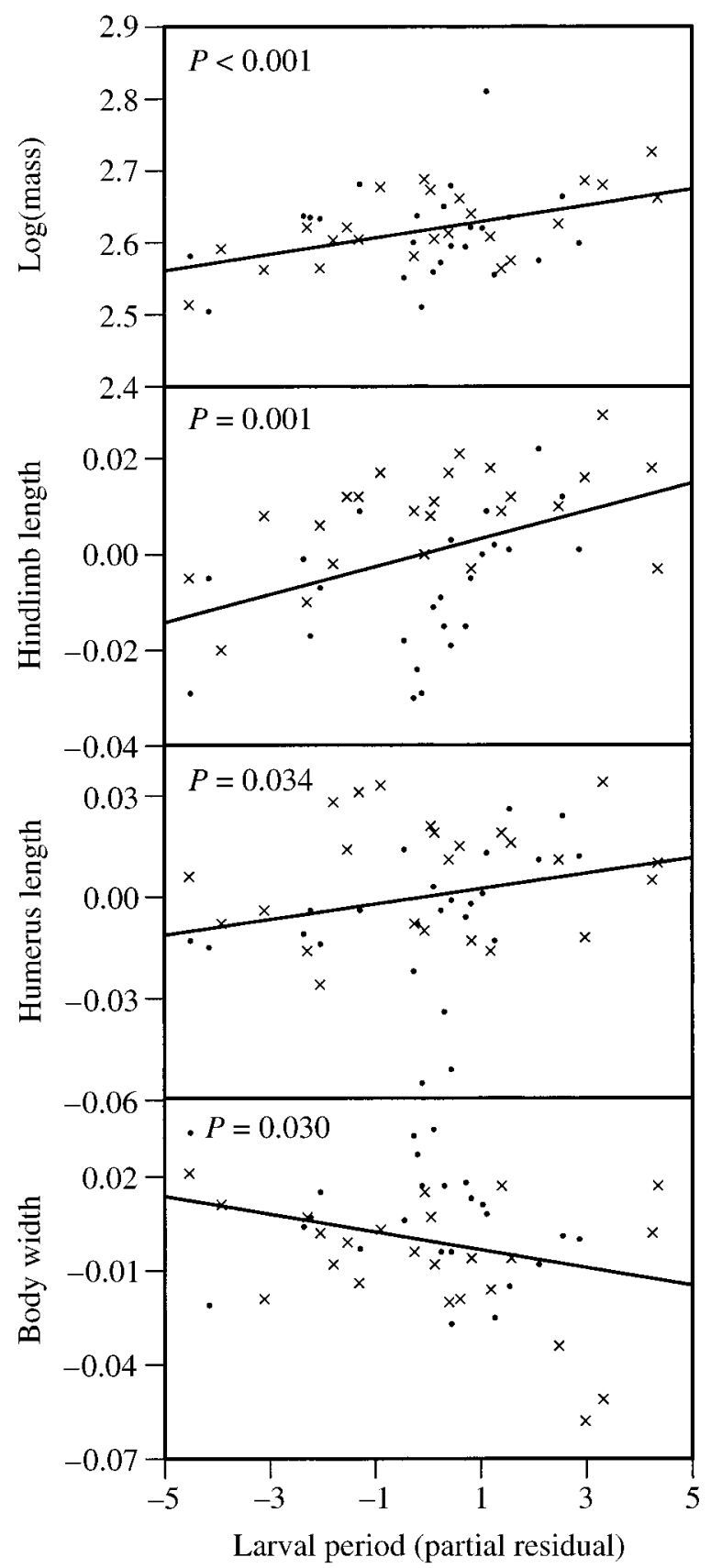

FIG. 2. The effect of larval period (as a partial residual) on several metamorphic traits in wood frogs: mass, hindlimb length, humerus length, and body width. Larvae were reared in either the presence $(X)$ or absence $(\bullet)$ of caged predators. Data are partial residuals from the multivariate multiple regression analysis to isolate the effect of only the larval period on the metamorphic traits.

expressed later in development. The trait correlation analysis produced three major patterns. First, metamorph mass was positively affected by both larval mass and larval period, indicating that large larvae maintain their size advantage through metamorphosis and that 
TABLE 2. Univariate regression coefficients from the regression analysis that examined the effect of larval traits of wood frogs (at day 35) on the subsequent metamorphic traits of wood frogs.

\begin{tabular}{|c|c|c|c|c|}
\hline \multirow[b]{2}{*}{ Metamorphic trait } & \multicolumn{4}{|c|}{ Larval trait } \\
\hline & $\begin{array}{l}\text { Tail } \\
\text { length }\end{array}$ & $\begin{array}{l}\text { Body } \\
\text { length }\end{array}$ & $\begin{array}{c}\text { Larval } \\
\text { mass }\end{array}$ & $\begin{array}{l}\text { Larval } \\
\text { period }\end{array}$ \\
\hline Hindlimb length & -0.194 & 0.100 & 0.006 & 0.003 \\
\hline Hindlimb width & -0.199 & 0.213 & -0.082 & 0.003 \\
\hline Forelimb length & -0.569 & 1.164 & -0.011 & 0.002 \\
\hline Forelimb width & -0.468 & 1.155 & -0.098 & 0.002 \\
\hline Body width & 0.188 & -0.813 & 0.042 & -0.003 \\
\hline Body length & -0.165 & 0.304 & -0.002 & 0.001 \\
\hline Head width & 0.131 & 0.225 & 0.027 & -0.001 \\
\hline Mouth width & -0.164 & 0.537 & -0.023 & 0.000 \\
\hline Metamorph mass & 0.790 & -0.055 & 0.739 & 0.011 \\
\hline
\end{tabular}

Notes: Coefficients in boldface are significant $(P<0.05)$. The table includes only those larval traits that had significant multivariate effects on metamorph morphology (see Table 1).

larvae can grow more when they have more time to forage. Second, longer larval periods caused increased relative hindlimb and forelimb size and decreased body width. Similar effects on mass-adjusted morphology have been found in other anurans. For example, Emerson (1986) found that longer larval periods in Rana sphenocephala were correlated to relatively longer hindlimbs, because of positive allometric growth of the body and limbs over ontogeny; when larval periods were extended, body growth slowed but limb growth continued. The underlying hormonal mechanism appears to be a prolonged exposure to high levels of thyroid hormones that promote limb growth during prometamorphosis (Brown and Frye 1969, Emerson 1986).

Third, larval morphology may constrain the development of certain metamorphic traits. Tadpoles with shorter bodies produced metamorphs with shorter and narrower forelimbs; however shorter larval bodies had no effect on the length of the metamorphic hindlimbs. In larval anurans, the forelimbs are developed completely inside of the body cavity and then exit through the body wall late in metamorphosis. Given that the tadpole body cavity is used for multiple functions including digestion (intestines typically compose more than half of the body cavity), space may be at a premium. If so, then forelimb development may be constrained by the length of the tadpole body but not by the width or depth of the body.

Interestingly, few other larval traits were related to the metamorphic traits. There was a negative correlation between tail length and forelimb length, but it is unclear what developmental pathway might account for this correlation. The remaining traits, including larval tail depth and the two muscle dimensions had no affect on metamorph morphology. We might expect a priori that these tail traits would affect metamorphic morphology since the tail is resorbed during metamorphosis and the tail biomass is converted to metamorph biomass. The lack of any correlations between the tail traits and the metamorph traits suggests that this converted biomass is not preferentially shunted to any particular metamorphic trait.

\section{The indirect effect of larval environments on metamorphic traits}

Using the correlations between larval and metamorphic traits, we can interpret why different tadpole environments affected the subsequent traits of metamorphic frogs. For example, odonate predators induce wood frogs and many other larval anurans to develop deeper tail fins, shorter bodies, lower mass, and longer larval periods than tadpoles exposed to predator-free environments (Smith and Van Buskirk 1995, McCollum and Van Buskirk 1996, Van Buskirk and Relyea 1998, Relyea and Werner 2000, Relyea 2000). The tadpoles in the current experiment responded similarly (Relyea 1998). Larval periods become extended because predator-induced changes in morphology and behavior cause a reduction in resource consumption (Skelly 1992, Werner and Anholt 1996, Relyea and Werner 1999), which can slow development and lengthen the time necessary to achieve the minimum size for metamorphosis (Wilbur and Collins 1973, Wilbur 1980, Werner 1986). Some of these predator-induced changes in larval traits could account for the subsequent changes in metamorph traits.

In the present study, metamorphs exposed to predator environments as larvae developed relatively longer and wider hindlimbs, longer forelimbs, and a narrower body than metamorphs exposed to predator-free environ-

TABLE 3. MANOVA results for the morphology of metamorphic wood frogs from eight populations previously reared (as tadpoles) in the absence or presence of caged predators.

\begin{tabular}{lrrr}
\hline \multicolumn{1}{c}{ Source } & \multicolumn{1}{c}{ df } & \multicolumn{1}{c}{$F$} & \multicolumn{1}{c}{$P$} \\
\hline Predator & $\mathbf{1 0 , 3 0}$ & $\mathbf{8 . 6}$ & $<\mathbf{0 . 0 0 1}$ \\
Hindlimb length & 1,39 & 29.4 & $<0.001$ \\
Hindlimb width & 1,39 & 4.2 & 0.047 \\
Forelimb length & 1,39 & 5.6 & 0.023 \\
Forelimb width & 1,39 & 0.4 & 0.518 \\
Body length & 1,39 & 0.9 & 0.339 \\
Body width & 1,39 & 9.9 & 0.003 \\
Head width & 1,39 & 0.0 & 0.972 \\
Mouth width & 1,39 & 1.7 & 0.194 \\
Larval period & 1,39 & 84.3 & $<0.001$ \\
Metamorphic mass & 1,39 & 0.5 & 0.500 \\
Population & $\mathbf{7 0 ,} \mathbf{1 8 1}$ & $\mathbf{1 . 7}$ & $\mathbf{0 . 0 0 3}$ \\
Hindlimb length & 7,39 & 5.3 & $<0.001$ \\
Hindlimb width & 7,39 & 3.6 & 0.005 \\
Forelimb length & 7,39 & 0.8 & 0.562 \\
Forelimb width & 7,39 & 1.1 & 0.398 \\
Body length & 7,39 & 2.8 & 0.018 \\
Body width & 7,39 & 7.0 & $<0.001$ \\
Head width & 7,39 & 1.3 & 0.284 \\
Mouth width & 7,39 & 2.7 & 0.023 \\
Larval period & 7,39 & 1.4 & 0.232 \\
Metamorph mass & 7,39 & 2.4 & 0.035 \\
\hline
\end{tabular}

Note: Multivariate tests are in boldface type, and univariate tests are in lightface type. 


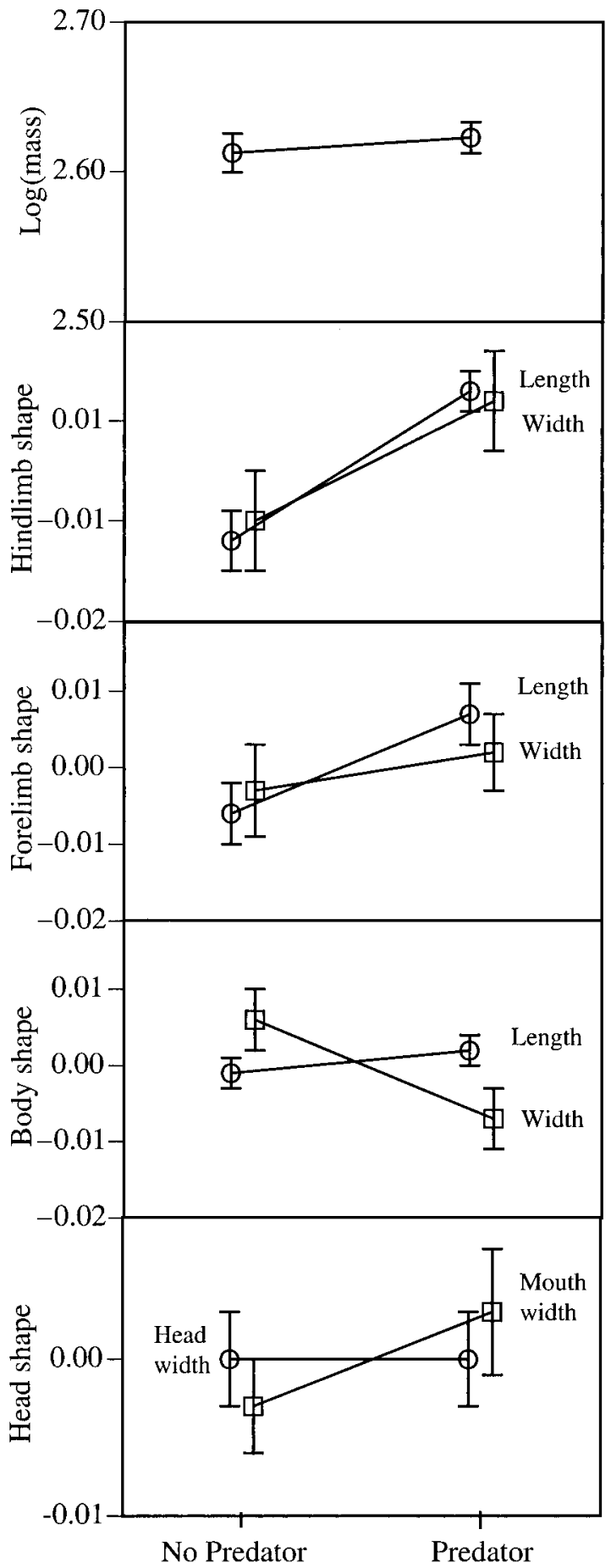

FIG. 3. The relative morphology of wood frog metamorphs previously reared in the presence or absence of caged dragonfly predators. Differences in overall size were removed prior to analysis by regressing all traits against individual mass and saving the residuals. Data are means $\pm 1 \mathrm{SE}$. ments as larvae. Thus, the aquatic predators had a direct effect on the morphology of the aquatic larvae and an indirect effect on the morphology of the terrestrial metamorphs. The predator-induced larval trait that exhibited the most widespread correlations with metamorphic morphology was the extended larval period; that is, (1) previous exposure to predators caused longer larval periods, and (2) longer larval periods were associated with relatively longer and wider hindlimbs, longer forelimbs, and narrower bodies. Thus, (3) previous exposure to predators indirectly caused metamorphs to develop relatively longer and wider hindlimbs, longer forelimbs, and narrower bodies. This is strong evidence that the effect of predators on metamorphic morphology occurred indirectly by affecting the larval period of the tadpoles.

The aquatic predators also induced several other larval traits (Relyea 1998, Van Buskirk and Relyea 1998), but most of these traits had no connection to the subsequent changes in the metamorphic traits. For example, one of the most striking effects of predators, the induction of a relatively deep tail fin, exhibited no association with any of the metamorphic traits. The predator-induced decrease in larval body length had a small negative (constraining) effect on forelimb length; however, this negative effect was opposed by a stronger positive effect of a predator-induced increase in larval period that increased the forelimb length. The net result was longer forelimbs. Thus, while the change in larval body length had an effect on forelimb length, the dominant mechanism driving change in forelimb length appears to be the predator-induced elongation of the larval period. Predators also induced lower tadpole mass at $35 \mathrm{~d}$, but the concomitant extended larval period resulted in metamorphs emerging from larval predator environments at a similar mass to metamorphs emerging from predator-free environments.

We can make testable predictions concerning the effect of other larval environments on metamorph morphology to test the generality that larval period is the mechanism that causes morphological changes in adults. For example, competitors also cause an extended larval period in tadpoles (Adolph 1931, Wilbur and Collins 1973, Smith-Gill and Berven 1979, Dash and Hota 1980, Sokol 1984), but they induce tadpoles to develop the opposite morphology from that induced by predators (shallow tails and long bodies in Hyla versicolor and Rana sylvatica; R. A. Relyea, unpublished manuscript). Competitor-induced tadpoles should develop longer limbs and narrower bodies due to their extended larval period, but be less constrained in forelimb development due to their longer larval body. Therefore, while predators and competitors induce anurans to develop opposite larval morphology, they should induce very similar metamorph morphology. In support of this prediction, Emerson (1986) found that Rana sphenocephala reared under increased 
larval competition produced metamorphs with longer hindlimbs (per unit mass).

\section{Are the metamorphic responses adaptive?}

Whereas larval responses to predators are adaptive responses that reduce predation risk (McCollum and Van Buskirk 1996, Van Buskirk et al. 1997, Van Buskirk and Relyea 1998), it is unlikely that the metamorphic responses are antipredator adaptations since the larval predation risk should be unrelated to metamorph predation risk on land. This lack of predationrisk correlation should hold not only for larval anurans, but also for the wide variety of organisms that possess complex life cycles (Werner 1986).

Little is known about the functional importance of the trait changes that the metamorphs exhibited. In comparisons of populations or species, limb length increases of $>10 \%$ result in increased jumping ability, but smaller increases do not (Stokely and Berberian 1953, Zug 1972, Emerson 1978, 1986). However, it is unknown whether predator-induced changes in metamorph limb length (and limb width) might affect jumping ability, and this is an area in need of further study. In the current study, the increases in hindlimb and forelimb length were 3-4\%; therefore, the wood frog metamorphs that developed longer limbs may not have possessed increased jumping ability. Moreover, it remains to be shown whether increased jumping ability has any adaptive value (Emerson et al. 1988). If longer limbs enable metamorphs to escape terrestrial predators better, this phenomenon might be best viewed as a correlated response to adaptive changes in larval traits (Lande and Arnold 1983, Arnold and Wade 1984a, b).

An alternative hypothesis is that the metamorphic responses are not responses to larval predators but are adaptive responses to an extended larval period. For example, predators and competitors induce an extended larval period and both result in metamorphs possessing relatively long limbs. Because an extended larval period can result in smaller size at sexual maturity (i.e., there is less time to grow in the terrestrial environment), lower terrestrial survivorship, and increased susceptibility to pond drying in larval anurans (Berven and Gill 1983, Smith 1983, Newman 1988, Semlitsch et al. 1988), the metamorphic responses to an extended larval period may improve their terrestrial performance when the period of terrestrial growth has been reduced. This hypothesis has yet to be tested.

\section{CONCLUSIONS}

Phenotypically plastic responses are extremely common in nature, occurring in nearly every taxa ever examined (Bradshaw 1965, West-Eberhard 1989, Travis 1994, Schlichting and Pigliucci 1998). When we examine the lasting effects of phenotypic plasticity in organisms with complex life cycles, the adaptiveness of these lasting effects should depend on the early environment's ability to predict later environmental con- ditions. When the early environment is a good predictor of later environmental conditions (e.g., crowding, photoperiod), there should evolve an adaptive link between life stages, resulting in individuals possessing adaptive traits later in development (Richards and Waloff 1954 , Harrison 1980, Denno and Roderick 1992). However, when the early environment is not a good predictor of later environmental conditions (e.g., aquatic vs. terrestrial predation risk), there should not be an adaptive link between life stages, resulting in individuals possessing nonadaptive traits later in development. In this case, the later traits are altered simply because they are developmentally connected to the environmentally altered early traits.

Because performance is the product of an individual's traits at a particular life stage, it is important that we identify connections between traits in different life stages. Such a mechanistic approach allows one to make testable predictions about how environmental induction of early traits should subsequently affect traits and performance later in development. By taking this approach, we will develop new hypotheses for developmental pathways between life stages and gain a new appreciation for the lasting effects of adaptive plasticity.

\section{ACKNOWLEDGMENTS}

I thank Jason Moll for assistance with the field work and Ronald Nussbaum and Richard Alexander for providing access to the E. S. George Reserve. Keith Wittkopp and Nina Misuraca did an outstanding job digitizing the larvae and metamorphs, respectively. Comments by J. David Allan, Deborah Goldberg, Ronald Nussbaum, Scott Peacor, and Earl Werner greatly improved the manuscript. This work was supported by University of Michigan research grants, Sigma Xi research grants and NSF grant DEB-9408397 to E. E. Werner.

\section{Literature Cited}

Adolph, E. 1931. The size of the body and the size of the environment in the growth of tadpoles. Biological Bulletin (Woods Hole) 61:350-375.

Arnold, S. J., and M. J. Wade. 1984a. On the measurement of natural and sexual selection: theory. Evolution 38:709719.

Arnold, S. J., and M. J. Wade. 1984b. On the measurement of natural and sexual selection: applications. Evolution 38: $720-734$.

Bernardo, J. 1994. Experimental analysis of allocation in two divergent, natural salamander populations. American Naturalist 143:14-38.

Berven, K. A. 1982a. The genetic basis of altitudinal variation in the wood frog Rana sylvatica. I. An experimental analysis of life history traits. Evolution 36:962-983.

Berven, K. A. 1982b. The genetic basis of altitudinal variation in the wood frog Rana sylvatica. II. An experimental analysis of larval development. Oecologia 52:360-369.

Berven, K. A., and D. E. Gill. 1983. Interpreting geographic variation in life-history traits. American Zoologist 23:8597.

Blouin, M. S., and M. L. G. Loeb. 1991. Effects of environmentally induced development-rate variation on head and limb morphology in the green tree frog, Hyla cinerea. American Naturalist 138:717-728.

Bookstein, F. L. 1989. "Size and shape": a comment on semantics. Systematic Zoology 38:173-180. 
Bradshaw, A. D. 1965. Evolutionary significance of phenotypic plasticity in plants. Advances in Genetics 13:115155.

Brown, P., and B. Frye. 1969. Effects of prolactin and growth hormone on growth and metamorphosis of tadpoles of the frog Rana pipiens. General and Comparative Endocrinology 13:126-138.

Crill, W. D., R. B. Huey, and G. W. Gilchrist. 1996. Withinand between-generation effects of temperature on the morphology and physiology of Drosophila melanogaster. Evolution 50:1205-1218.

Dash, M. C., and A. K. Hota. 1980. Density effects on the survival, growth rate, and metamorphosis of Rana tigrina tadpoles. Ecology 61:1025-1028.

de Moed, G. H., G. De Jong, and W. Scharloo. 1997. The phenotypic plasticity of wing size in Drosophila melanogaster: the cellular basis of its genetic variation. Heredity 79:260-267.

Denno, R. F., and G. K. Roderick. 1992. Density-related dispersal in planthoppers: effects of interspecific crowding. Ecology 73:1323-1334.

Dudley, S. A., and J. Schmitt. 1996. Testing the adaptive plasticity hypothesis: density-dependent selection on manipulated stem length in Impatiens capensis. American Naturalist 147:445-465.

Emerson, S. B. 1978. Allometry and jumping in frogs: helping the twain to meet. Evolution 32:551-564.

Emerson, S. B. 1986. Heterochrony and frogs: the relationship of a life history trait to morphological form. American Naturalist 127:167-183.

Emerson, S. B., J. Travis, and M. Blouin. 1988. Evaluating a hypothesis about heterochrony: larval life-history traits and juvenile hind-limb morphology in Hyla crucifer. Evolution 42:68-78.

Gosner, K. L. 1960. A simplified table for staging anuran embryos and larvae with notes on identification. Herpetologica 16:183-190.

Harrison, R. G. 1980. Dispersal polymorphisms in insects. Annual Review of Ecology and Systematics 11:95-118.

Lande, R., and S. J. Arnold. 1983. The measurement of selection on correlated characters. Evolution 37:1210-1226.

Maurer, E. F., and A. Sih. 1996. Ephemeral habitats and variation in behavior and life history: comparisons of sibling salamander species. Oikos 76:337-349.

McCollum, S. A., and J. Van Buskirk. 1996. Costs and benefits of a predator-induced polyphenism in the gray tree frog Hyla chrysocelis. Evolution 50:583-593.

Newman, R. A. 1988. Adaptive plasticity in development of Scaphiopus couchii tadpoles in desert ponds. Evolution 42: 774-783.

Relyea, R. A. 1998. Phenotypic plasticity in larval anurans. Dissertation. University of Michigan, Ann Arbor, Michigan, USA.

Relyea, R. A. 2000. Trait-mediated indirect effects in larval anurans: reversing competition with the threat of predation. Ecology 81:2278-2289.

Relyea, R. A. 2001a. Morphological and behavioral plasticity of larval anurans in response to different predators. Ecology 82:523-540.

Relyea, R. A. 2001b. The relationship between predation risk and antipredator responses in larval anurans. Ecology 82: 541-554.

Relyea, R. A. 2002. Local population differences in phenotypic plasticity: predator-induced changes in wood frog tadpoles. Ecology, in press.

Relyea, R. A., and E. E. Werner. 1999. Quantifying the relation between predator-induced behavior and growth performance in larval anurans. Ecology 80:2117-2124.

Relyea, R. A., and E. E. Werner. 2000. Morphological plas- ticity of four larval anurans distributed along an environmental gradient. Copeia 2000:178-190.

Richards, O. W., and N. Waloff. 1954. Studies on the biology and population dynamics of British grasshoppers. Anti-Locust Bulletin 17:1-182.

Roff, D. A. 1986. The evolution of wing dimorphism in winged insects. Evolution 40:1009-1020.

Roff, D. A. 1992. The evolution of life histories: theory and analysis. Chapman \& Hall, New York, New York, USA.

Roff, D. A. 1998. Evolutionary quantitative genetics. Chapman \& Hall, New York, New York, USA.

Schlichting, C. D., and M. Pigliucci. 1998. Phenotypic evolution: a reaction norm perspective. Sinauer, Sunderland, Massachusetts, USA.

Semlitsch, R. D., R. N. Harris, and H. M. Wilbur. 1990. Paedomorphosis in Ambystoma talpoideum: maintenance of population variation and alternative life-history pathways. Evolution 44:1604-1613.

Semlitsch, R. D., D. C. Scott, and J. H. K. Pechmann. 1988. Time and size at metamorphosis related to adult fitness in Ambystoma talpoideum. Ecology 69:184-192.

Skelly, D. K. 1992. Field evidence for a cost of behavioral antipredator response in a larval amphibian. Ecology 73: 704-708.

Smith, D. C. 1983. Factors controlling tadpole populations of the chorus frog (Pseudacris triseriata) on Isle Royale, Michigan. Ecology 64:501-510.

Smith, D. C., and J. Van Buskirk. 1995. Phenotypic design, plasticity, and ecological performance in two tadpole species. American Naturalist 145:211-233.

Smith-Gill, S. J, and K. A. Berven. 1979. Predicting amphibian metamorphosis. American Naturalist 113:563-585.

Sokol, A. 1984. Plasticity in the fine timing of metamorphosis in tadpoles of the hylid frog, Litora ewingi. Copeia 1984: 868-873.

Spitze, K. 1992. Predator-mediated plasticity of prey lifehistory and morphology: Chaoborus americanus predation on Daphnia pulex. American Naturalist 139:229-247.

Stearns, S. C. 1992. The evolution of life histories. Oxford University Press, New York, New York, USA.

Stokely, P. S., and J. F. Berberian. 1953. On the jumping ability of frogs. Copeia 1953:187.

Taylor, F. 1986. Toward a theory for the timing of hibernal diapuse. Pages 236-258 in F. Taylor and R. Karban, editors. The evolution of insect life cycles. Springer, Berlin, Germany.

Tollrian, R. 1995. Predator-induced morphological defenses: costs, life history shifts, and maternal effects in Daphnia pulex. Ecology 76:1691-1705.

Tollrian, R., and D. Harvell. 1999. The ecology and evolution of inducible defenses. Princeton University Press, Princeton, New Jersey, USA.

Travis, J. 1994. Evaluating the adaptive role of morphological plasticity. Pages $99-122$ in P. C. Wainwright and S. M. Reilly, editors. Ecological morphology. The University of Chicago Press, Chicago, Illinois, USA.

Travis, J., S. B. Emerson, and M. Blouin. 1987. A quantitative-genetic analysis of larval life-history traits in Hyla crucifer. Evolution 41:145-156.

Van Buskirk, J., S. A. McCollum, and E. E. Werner. 1997. Natural selection for environmentally-induced phenotypes in tadpoles. Evolution 52:1983-1992.

Van Buskirk, J., and R. A. Relyea. 1998. Natural selection for phenotypic plasticity: predator-induced morphological responses in tadpoles. Biological Journal of the Linnean Society 65:301-328.

Werner, E. E. 1986. Amphibian metamorphosis: growth rate, predation risk, and the optimal size at transformation. American Naturalist 128:319-341.

Werner, E. E., and B. R. Anholt. 1996. Predator-induced be- 
havioral indirect effects: consequences to competitive interactions in anuran larvae. Ecology 77:157-169.

West-Eberhard, M. J. 1989. Phenotypic plasticity and the origins of diversity. Annual Review of Ecology and Systematics 20:249-278.

Wilbur, H. M. 1980. Complex life cycles. Annual Review of Ecology and Systematics 11:67-93.
Wilbur, H. M., and J. P. Collins. 1973. Ecological aspects of amphibian metamorphosis. Science 182:1305-1314.

Zug, G. R. 1972. Anuran locomotion: structure and function. I. Preliminary observations on relation between jumping and osteometrics of appendicular and postaxial skeleton. Copeia 1972:613-624. 